\title{
A Method for Power Conditioning with Harmonic Reduction in Microgrids
}

\author{
I. D. Bouloumpasis ${ }^{1}$, P. N. $\operatorname{Vovos}^{1}$, K. G. Georgakas ${ }^{1}$ and N. A. $\operatorname{Vovos}^{1}$ \\ ${ }^{1}$ Department of Electrical and Computer Engineering \\ University of Patras, \\ GR 26500 Rion- Patras (Greece) \\ Phone/Fax number: +0030 2610996403, 2610996893, e-mail: bouloumpasis@ece.upatras.gr, panagis@upatras.gr, \\ kgeorgakas@hol.gr, n.a.vovos@ece.upatras.gr
}

\begin{abstract}
This paper presents a control method of Renewable Energy Sources (RES) to reduce the harmonic content of the distribution system to which are connected, such as a Microgrid. By this method the RES is acting as a Power Conditioner and its supplying system consists of a buck-boost converter connected back-to-back to a polarity swapping inverter. A RES or a Distributed Generator (DG) such as a microturbine is synchronized to the distribution system, which is assumed to be distorted by a high-order voltage harmonic. Utilizing the proposed method, the RES not only exports its output power to the grid, but also reduces the existing harmonic distortion, improving voltage quality at the Point of Common Coupling (PCC). Simulations in Matlab/Simulink platform have been performed in order to verify the effectiveness of the suggested approach to reduce harmonic content.
\end{abstract}

\section{Key words}

Power Conditioner, Harmonic Reduction, Microgrid, Power Quality, Buck Boost Converter.

\section{Introduction}

Nowadays there is a significant trend for distributed and renewable generation. These types of generation have many advantages compared with conventional generation, such as low fuel cost, small or no environmental footprint and higher efficiency. The volatility of those power resources together with some technical difficulties interfacing them to the distribution system, created a worldwide scientific interest in the formation of a new type of grid, the microgrid [1]. In its final form, the microgrid will be able to accommodate RES without disturbing system operation. Microgrids are supposed to interconnect with the already existing grids, maintaining at the same time the capability to isolate themselves from the grid (i.e. islanding) whenever a fault jeopardizes their security or the security of the grid to which they are connected.
A lot of power conditioners and active filters have been proposed worldwide in order to alleviate the distribution system from the problem of high order harmonic distortion and improve power quality. Harmonic distortion occurs due to a number of reasons, such as loads' behavior, their converter's switching operation and the switching operation of the RES' inverters connected to the grid. The use of inverters may have a lot of advantages, such as fast voltage and frequency regulation, but also displays an important drawback. They export high order harmonics to the grid due to the switching operation of the semiconductors included in them. Similarly, harmonic distortion occurs due to loads supplied by converters as well to their inductive behavior. Harmonic distortion leads to poor power quality to the end user.

Many power conditioners and active filters configurations have been implemented, but few of them deal with grid's power quality improvement. Instead, they focus in harmonic cancellation and power quality improvement of critical loads against grid's distortions. In reference [2], a harmonic compensation method, based on closed-loop synchronous frame control of line currents as well as a selective open-loop approach based on load current sensing are presented, concluding that the proposed method is robust enough for compensating distortions provoked by non-linear loads, but it operates only when the distorting loads have slowly varying high-order harmonics. In [3], a signal processing system for harmonic and current components calculation is introduced. This system is adopted as a part of a single-phase active power filter and results in a satisfying compensation, although it may lack implementation ease. Moreover, in [4] an interesting approach has been made, proposing a multifunctional series power quality conditioner. This conditioner consists of one series and one shunt part and is based on an asymmetry cascade multilevel inverter, which has low switching losses and implementation difficulty. This conditioner can efficiently compensate load harmonic current and improve power quality of the end user, but it does not take into consideration a potential 
inductive source, such as a wind turbine. Reference [5] suggests an active filter based on a space vector modulation (SVM) controlled converter for harmonic compensation and power factor correction, but it exhibits robust behavior only with balanced dc side voltages. A robust adaptive control strategy of active filters for harmonic compensation, power factor correction and balancing of nonlinear loads is implemented in [6]. It shows satisfying performance and has fewer sensors, but a bulky capacitor bank is used. Moreover, an alternative implementation of active filters in High-Voltage Direct Current (HVDC) application in dc transmission systems has been made, showing widely developed applicability of such devices and making clear the importance of harmonic compensation and power quality improvement [7].

Besides active filters, a large number of power conditioners has been proposed worldwide in order to improve power quality and reduce harmonic content of critical loads against utility system distortions or DG unbalances [8] - [15]. The aim of these conditioners is to protect certain loads from poor power quality, but none of them deals with the alleviation of grid's high-order harmonic distortion. Reference [16] suggests a method that uses residential PV panels in order to compensate harmonic distortion in distribution system which is produced by nonlinear loads and/or capacitor banks installation. Virtual harmonic resistance control scheme is implemented to achieve harmonic compensation. A virtual harmonic impedance control scheme which would be suitable for microgrid implementation is also mentioned. Moreover, authors present and compare two different harmonic compensation schemes, in order to determine which method will be suitable for usage in any case, although system's load must been known so that the decision can be made. These methods are distributed compensation [17] and end-of-line compensation [18] [19], respectively. This idea might be generalized by using other types of RES or DGs for this purpose. Actually only this work deals with a similar to our work issue.

The converter configuration proposed in [20] has been used in this work in order to reduce the harmonic content at the PCC, so that the total harmonic distortion (THD) index is decreased. This is achieved by using the proposed power conditioner connected with a RES. This power conditioner injects the active power produced by the RES to the grid and at the same time supplies the reactive power compensation needed. It consists of a dc to dc buck-boost chopper connected to the grid through a simple polarity changing inverter. The buck boost chopper operates in a high switching frequency while the polarity swapping inverter operates in a low one. Consequently, switching loses are limited to the semiconductor of the buck boost chopper while the corresponding losses of inverter's semiconductors are negligible. Moreover, the proposed power conditioner combines harmonic reduction along with RES connection to the grid, enhancing clean energy participation in it. Thus, this topology operates more efficiently than the conventional ones.
The remaining of this paper is organized as follows. Section 2 describes the microgrid structure and configuration, the operation of all the parts of the proposed power conditioner as well as the synchronization procedure. Section 3 presents the simulation results in the MATLAB/SIMULINK platform. Simulations results verify the proposed method. Conclusions are drawn in section 4 .

\section{The Suggested Power Conditioner and the Studied Microgrid}

In this section the topology and operation of the parts of the proposed power conditioner, as well as its grid synchronization procedure are described.

\section{A. Topology and Operation of the Power Conditioner}

The suggested power conditioner is connected to the PCC. The aim is to alleviate the already existing high order harmonics in order to cope with Distribution and Utilization standards (IEEE519-92) [21]. These standards dictate that the percentage of the Total Harmonic Distortion (THD) in every node of the system and for every device which is connected to it should be less than $5 \%$. Fig. 1 shows the configuration of the studied system. The studied system consists of the power conditioner supplied by a RES and it is connected through an impedance to a weak and harmonically distorted microgrid. $\mathrm{R}_{\mathrm{L}}$ emulates the load at the PCC.

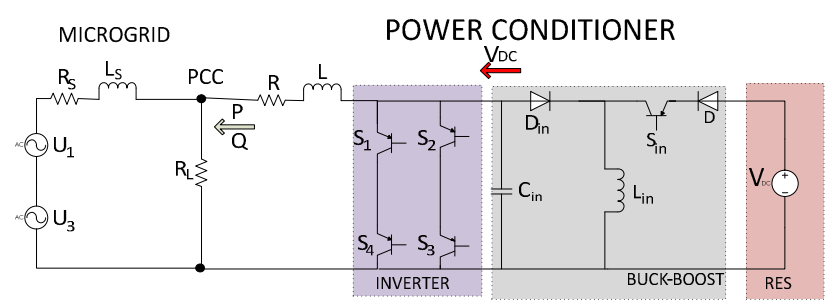

Fig. 1. Configuration of the studied system.

The dc voltage produced by the RES is being fed to a $\mathrm{dc} / \mathrm{dc}$ buck -boost converter. The topology of the buckboost converter is shown in fig. 1 . This converter operates at a high switching frequency (e. g. $20 \mathrm{KHz}$ ). The duty cycle $\mathrm{D}$ is being continuously calculated under the above mentioned frequency using Pulse Width Modulation (PWM) technique [20], and it is given by:

$$
D=\frac{V_{d c, o u t}}{V_{d c, o u t}+V_{d c, \text { in }}}
$$

This constant calculation takes place in order to create a rectified voltage. This voltage is being fed to the polarity swapping inverter that operates at a low switching frequency $(50 \mathrm{~Hz})$ and inverts the dc voltage to ac. Furtermore, an on-line Fast Fourier Analysis (FFT) of the harmonic content at the PCC takes place, so that information of the exact amplitude and angle of PCC's 
harmonics is obtained. The power conditioner injects the exact amount of high order harmonic, so that the THD is reduced. In order to eliminate the existing distortion the injected harmonic component will have the same amplitude but a $180^{\circ}$ phase shift in relation with the one existing in the grid. This sine wave is being fed into the 20 $\mathrm{KHz}$ PWM duty cycle calculation, so that proper pulses are created in order to shape converter's output sine voltage. The inverter is only responsible for swapping the output voltage of the buck-boost converter so that a suitable ac voltage is generated. Therefore, the switching frequency is $50 \mathrm{~Hz}$ as grid's frequency. Inverter's low frequency is one of the major advantages of this power conditioner, as it combines harmonic reduction along with low switching losses. A single phase full-bridge topology was selected. This topology consists of four semiconductors which are triggered in pair $\left(S_{1}-S_{4}, S_{2}-S_{3}\right)$. The inverter is synchronized with the chopper in order to change output voltage polarity. Every time buck boost's voltage becomes zero (or at least reaches its minimum value), inverter's conducting pair changes. The topology of the used inverter is shown in fig. 1.

In fig. 2 an example of inverter's operation is illustrated, showing: (a) buck boost's output voltage, (b) $\mathrm{S}_{1} \mathrm{~S}_{4}$ semiconductors pulses, (c) $\mathrm{S}_{2} \mathrm{~S}_{3}$ semiconductors pulses (d) inverter's output voltage.

(a)

(b)

(c)

(d)

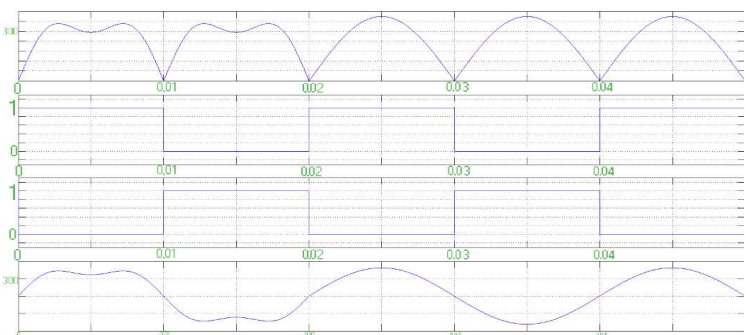

Fig. 2. (a) Buck boost's output voltage, (b) $S_{1}, S_{4}$ pulses, (c) $S_{2}$, $\mathrm{S}_{3}$ pulses, (d) inverter's output voltage.

\section{B. Harmonic Cancellation Method}

The generation of the required harmonic component is feasible via proper pulse modulation of the buck-boost conditioner. The key idea is that proper trigger pulse generation will lead the converter to create a voltage containing the suitable for the occasion mirror harmonic content, resulting in harmonic compensation. Buckboost's trigger pulses are being initially created by the comparison of the rectified PCC's voltage signal and the $20 \mathrm{KHz}$ reference triangle, taking into consideration the duty cycle D of buck-boost, given by (1). After synchronization an FFT analysis of PCC's voltage takes place. A sine wave, the mirror harmonic of grid's high order harmonic component that has the same frequency and amplitude but a $180^{\circ}$ phase shift from it, is added to the $50 \mathrm{~Hz}$ sine signal during the pulse generation modulation. Afterwards, FFT is carried out again so that information about the alternation of the harmonic content is obtained.
To clarify this procedure let us assume that node's high harmonic component is $h_{a}(t)$ and that power conditioner injects harmonic component $\mathrm{h}_{\mathrm{b}}(\mathrm{t})$ to the PCC so that total harmonic content would be $h_{c}(t)$. So it would be:

$$
\begin{aligned}
& h_{A}(t)=A \sin (2 \pi f t+a) \\
& h_{B}(t)=B \sin (2 \pi f t+b) \\
& h_{C}(t)=C \sin (2 \pi f t+c)
\end{aligned}
$$

in which A,B,C and a, b, c are the amplitudes and the phase angles of the aforementioned signals respectively. Because all these signals have the same frequency $f$, previous functions can be converted into phasors:

$$
\begin{aligned}
& h_{A}(t)=A e^{j a} \\
& h_{B}(t)=B e^{j b} \\
& h_{C}(t)=C e^{j c}
\end{aligned}
$$

So it can be assumed that the harmonic content $\mathrm{C}$ of the output can be calculated by:

$$
C e^{j c}=A e^{j a}+B e^{j b}
$$

and finally amplitudes A, B, C and phase angles a, b, c are related with each other by the equations:

$$
\begin{aligned}
& A \cos (a)+j A \sin (a)+ \\
& B \cos (b)+j B \sin (b)=C \cos (c)+j C \sin (c) \Rightarrow \\
& \left\{\begin{array}{l}
C \cos c=A \cos (a)+B \cos (b) \\
C \sin c=A \sin (a)+B \sin (b)
\end{array} \Rightarrow\right. \\
& \left\{\begin{array}{c}
a=\tan ^{-1}\left(\frac{C \sin (c)-B \sin (b)}{C \cos (c)-B \cos (b)}\right) \\
A=\frac{C \cos (c)-B \cos (b)}{\cos (a)}
\end{array}\right.
\end{aligned}
$$

Fig. 3 explains the mentioned theoretical analysis. It shows the distorted ac voltage of PCC (a), its high order harmonic component (b), the mirror harmonic to be injected (c) and the ac voltage at PCC after the harmonic compensation (d).

(a)

(b)

(c)

(d)

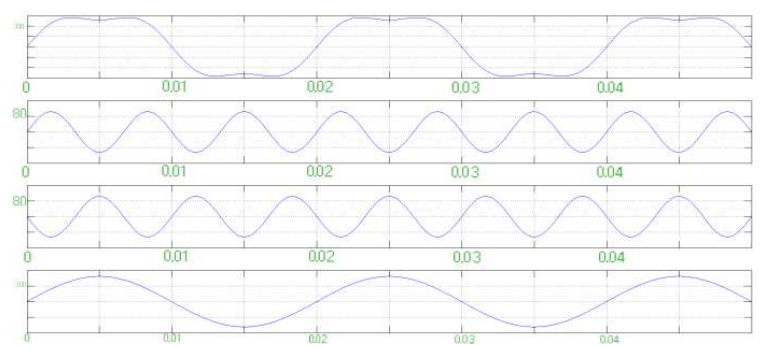

Fig. 3. (a) Distorted ac voltage at the PCC before compensation, (b) $3^{\text {rd }}$ harmonic component at the PCC before compensation, (c) mirror $3^{\text {rd }}$ harmonic component injected to the PCC, (d) ac voltage at the PCC after harmonic compensation.

During the initial iteration, no mirror harmonic is supplied. According to (6), when $\mathrm{B}=\mathrm{b}=0, \mathrm{~A}=\mathrm{C}$ and $\mathrm{a}=\mathrm{c}$. An FFT analysis of PCC's harmonic content (c and C) should be executed constantly, so that power conditioner responds immediately at any random change of harmonic content ( $\mathrm{a}$ and A). Until the power conditioner is 
synchronized with the microgrid (see section 2.C) there is no harmonic injection, in order to avoid overcurrent flow that may harm the equipment. After synchronization, compensation begins and the previously described steps are being followed. It has to be underlined that this methodology can be extended to more than one high-order harmonics. In this work though, compensation of only $3^{\text {rd }}$ harmonic has applied for simplicity.

Fig. 4 shows typical pulse creation waveforms for buckboost converter, before harmonic injection (0-0.02s) and during harmonic injection (after 0.02s). Fig. 4(a) shows the $\mathrm{V}_{\mathrm{dc} \text {,out }}$ created by the buck boost converter. This voltage is the one that will be inverted by the polarity swapping inverter. Fig. 4(b) shows the comparison of duty cycle D, continuously calculated by (1), with the reference triangle, so that the pulses controlling the buck boost converter are obtained, as shown in fig. 4(c).

(a)

(b)

(c)

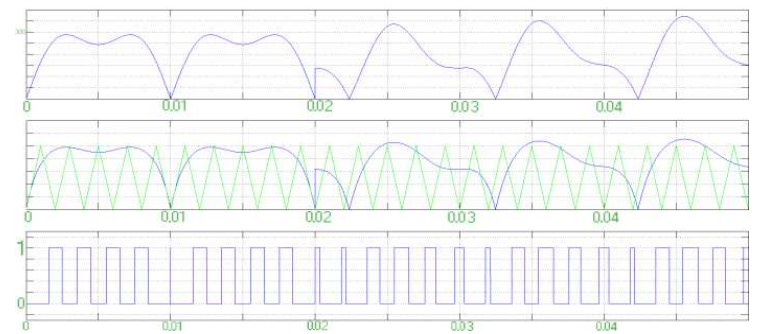

Fig. 4. (a) $V_{d c, o u t}$ created by the buck boost converter, (b) comparison of duty cycle D with $20 \mathrm{KHz}$ reference triangle, (c) created pulses.

\section{Synchronization}

Interconnection between Power Conditioner and grid takes place at the PCC when certain synchronization criteria are fulfilled. According to standards, in order to synchronize two or more electrical parts, the following conditions must be satisfied: voltage magnitudes should differ less than $0.5 \%$, frequency deviation must not be greater than $0.1 \mathrm{~Hz}$, and phase angle difference must not be greater than 10 degrees. The most common way to synchronize two electrical parts is by using a PhaseLocking Loop (PLL) algorithm. PLL is an algorithm which actually "locks" the phase angle of its output signal to the phase angle of its input signal.

In figs. 5 and 6 a typical block diagram and a typical control loop of a PLL are shown.

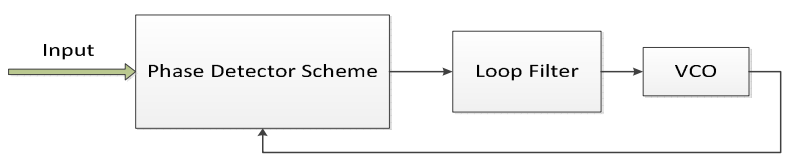

Fig. 5. Typical block diagram of a PLL.

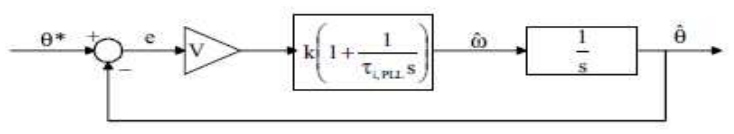

Fig. 6. Typical control loop of a PLL.
The phase difference between input and output signals is calculated by the phase detector and is passed through the loop filter. The error signal "e" drives a voltage-controlled oscillator (VCO) which generates the output signal. The phase detector may simply be a multiplier. Loop filter's output is a measure of the real phase difference between the two signals of interest. Ideally, such an error signal is small and a proportion of the real phase difference of the two signals [22]. A lot of different PLL algorithms have been proposed and used. Most popular among these techniques are Enhanced (EPLL) [23] - [25], Adaptive PLL (APLL) [26] - [28], Double -SOGI PLL [29], which seem to have a major impact in recent researches. This vast variety of different techniques and applications of PLL states that there is a lot of research interest in this particular field. In this work and for simplicity reasons, 1 -phase discrete PLLs existing in SIMULINK library have been used.

\section{Simulations-Results}

In order to verify the previously described theory, simulations have been performed in the Matlab/Simulink Platform.

The harmonically distorted microgrid was simulated by two AC sources connected in series and operating at 50 and $150 \mathrm{~Hz}$. 3rd harmonic $(150 \mathrm{~Hz})$ was selected to be compensated because it is frequently met in microgrids and it is one of the most difficult to deal with. So, microgrid's voltage has been chosen to be distorted by a $3^{\text {rd }}$ harmonic component in a large percentage of the fundamental harmonic $(15-25 \%)$ so that power conditioner's performance is examined. Grid's weakness is generally indicated by the Short Circuit Ratio (SCR). SCR is the ratio of the Short Circuit Capacity (SCC) of a system over its supplied active power. Here:

$$
S C R=\frac{S C C}{P_{P C}}
$$

where $\mathrm{P}_{\mathrm{PC}}$ is the amount of active provided at the PCC and SCC is microgrid's SCC. In this work SCR was chosen as a variable that decides the interaction between the microgrid and the power conditioner. A resistance $\left(\mathrm{R}_{\mathrm{L})}\right.$ has been placed as a load at the PCC, in order to avoid any passive load filtering, or generally any affection of it in reactive power flow study. A RES supplies power to the power conditioner and it is simulated by a $300 \mathrm{~V} \mathrm{dc}$ source. Insulated-Gate Bipolar Transistors (IGBTs) have been simulated as semiconductors for both the buck boost converter and the inverter. Two similar diodes have been used for the chopper. Chopper's inductance has been selected to be as low as $1 \mathrm{mH}$ and the capacitor $\mathrm{C}$ has been selected to be only $10 \mu \mathrm{F}$. Capacitor's value is small for two reasons. Firstly, to avoid the cost that a bulky capacitor would have and secondly to avoid stabilization of DC output buck-boost voltage, so that the intermitted behavior of a real RES would be emulated. However, this 
capacitance is big enough to protect the system from malfunctions, such as overvoltages and overcurrents.

The switching frequency of the buck boost converter was set at $20 \mathrm{kHz}$. This particular frequency was selected mainly for three reasons. Firstly, selected frequency is above acoustic frequencies in order to prevent any disturbing for the user noise. Secondly, this frequency is high enough, so that there will be an automatic filtering by converter's passive elements. Finally, this value is a tradeoff between the above mentioned requirements and moderate switching losses. The switching frequency of the inverter was set at $50 \mathrm{~Hz}$, as it has to match the voltage frequency at the PCC. Frequency and phase angle of both signals of interest are being measured on-line by two different 1-phase discrete PLLs. Moreover, rms values of these signals are computed. Having all the required information and if synchronization criteria are satisfied the power conditioner connects to the grid. The power conditioner is connected to the PCC through an inductance of similar to the one existing in the microgrid size, so that none part will be dominant over the other, but an interaction between them will occur.

At first, a $15 \%$ distortion of $3^{\text {rd }}$ harmonic was considered and $\mathrm{R}_{\mathrm{L}}$ was set to $100 \Omega$. $\mathrm{L}_{\mathrm{s}}$ was set to $45 \mathrm{mH}$ and $\mathrm{L}$ to 25 $\mathrm{mH}$. So, in this case SCR was 7.07. PCC's voltage, its $3^{\text {rd }}$ harmonic component and its THD are shown in fig. 7(a)(c) respectively.

(a)

(b)

(c)

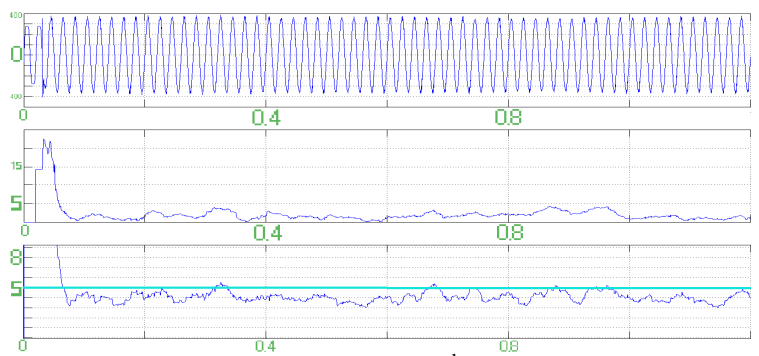

Fig. 7. (a) PCC's voltage, (b) PCC's $3^{\text {rd }}$ harmonic component, (c) PCC's THD.

It can be seen by fig. 7 that the proposed power conditioner, after a short transient time, achieves a harmonic reduction at the PCC, compensating PCC's THD below $5 \%$, as the standards dictate. Afterwards, harmonic distortion was set at $25 \%$ of the fundamental component $\mathrm{R}_{\mathrm{L}}$ was set to $75 \Omega, \mathrm{L}_{\mathrm{s}}$ to $73.7 \mathrm{mH}$ and $\mathrm{L}$ to 60 $\mathrm{mH}$. Thus $\mathrm{SCR}=3.2$. The results are illustrated in fig. 8 .

(a)

(b)

(c)

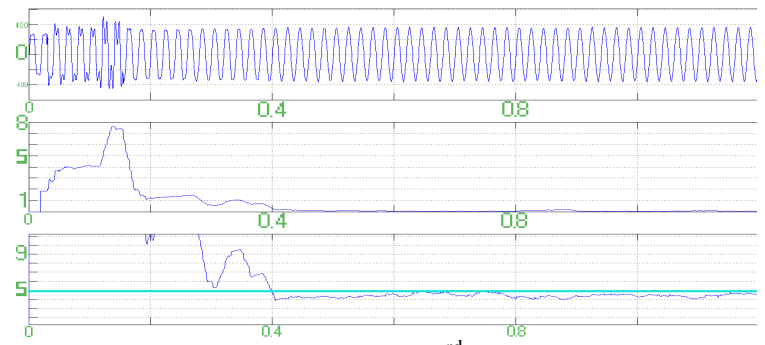

Fig. 8. (a) PCC's voltage, (b) PCC's $3^{\text {rd }}$ harmonic component, (c) PCC's THD.
It can be seen that in this case THD is reduced below 5\%, too. Here, transient time is longer because the distortion is more severe than the previous case. From both previous cases we can see that while microgrid is distorted only by a $3^{\text {rd }}$ harmonic and PCC's harmonic component is reduced in both cases below $2 \%$, THD remains below but close to $5 \%$. This happens due to power conditioner's switching operation and L-C interaction with the grid inductances that create higher harmonics $\left(5^{\text {th }}, 7^{\text {th }}\right.$, e.t.c $)$.

\section{Conclusion}

A novel system of a RES connected with an electronic converter was proposed to act as a power conditioner, through a pulse technique of high harmonic injection to a microgrid. Main advantages of the proposed topology are its robustness, its converter's low switching losses and the simplicity of its harmonic control. Its performance was verified by a series of simulations. The simulation results proved robustness and efficient operation of the proposed power conditioner under different and difficult conditions, such as a severally distorted grid. Simulation results show that the power conditioner achieves harmonic compensation that leads to a Total Harmonic Distortion (THD) less than 5\%, as dictated by standards. Implementation of this configuration to future microgrids would alleviate the problem of high order harmonics. Power conditioner's operation in transients as well as its economical and technical evaluation should be examined in future research. Therefore, a RES (or generally a DG) which will be connected to a microgrid via this power conditioner will be able not only to export its generated power to the grid, but also improve power quality of the grid.

\section{References}

[1]T. Liang, C. Schwaegerl, S. Narayanan and J. H. Zhang, "From Laboratory Microgrid to Real Markets- Challenges and Opportunities," IEEE $8^{\text {th }}$ Intern. Confer. On Power Electron. And ECCE Asia (ICPE \& ECCE), pp. 264-271, 2011.

[2] P. Mattavelli and P. Tenti, "High performance active filters using selective harmonic control," IEEE, 2000.

[3] M. Krimi-Ghartemani, H. Mokthari, M.Reza Iravani and M.Sedighy, "A signal processing system for extraction of harmonics and reactive current of single-phase systems," IEEE Trans. Power Delivery, vol.19, no.3, pp. 979-984, Jul. 2004.

[4] H. Ding, X. Duan and Q. Zhu, "A multifunctional series power quality conditioner based asymmetry cascade multilevel inverter and its strategy," IEEE/PES Transmission and Distribution Conf. , Asia and Pacific, China, 2005.

[5] D. Iannuzzi, L. Piegari and P.Tricoli, "An active filter used for harmonic compensation and power factor connection: A control technique," IEEE, 2008. 
[6] R. L. A Ribeiro, C. C de Azevedo and R. M de Sousa, "A robust adaptive control strategy of active power filters for power-factor correction, harmonic compensation, and balancing of nonlinear loads," IEEE Trans. Power Electron. Vol. 27, no. 2, pp. 718-730, Feb. 2012.

[7] R. Kh. Antar, B.M Saied R. A. Khalil and G. A. Putrus, "HVDC link power quality improvement using a modified active power filter."

[8] C. Zhan, M. Wong, Z. Wang, Y. Han, "DSP control of power conditioner for improving power quality," IEEE, 2000.

[9] C. Chandhaket, Y. Konishi, K. Ogura, E. Hiraki and M. Nakaoka "A sinusoidal pulse width modulation inverter using three-winding high-frequency flyback transformer for PV conditioner," IEEE, 2003.

[10] T. Ahmed, S. Nagai, M. Nakaoka and H. W. Lee, "Twoswitch auxiliary Quasi-Resonant DC link snubber-assisted voltage source three-phase V-connection soft-switching sinewave inverter with bidirectional soft-switching chopper for solar PV power conditioner,” IEEE Ind. Electron. Conf., 2004

[11] N. A. Ahmed, H. W. Lee, T. Ahmed, E. Hiraki and M.Miyatake, "Dual-mode time-sharing one-stage single-phase power conditioner using sinewave tracked soft switching PWM boost chopper," IEEE/IAS, 2005.

[12] T. Ahmed, M. Nakaoka and S. Nagai ,"Utility grid interfaced PV power conditioner using boost chopper-four switch three phase inverter with a novel quasi resonant DC link snubber," IEEE, 2006.

[13] N. A. Ahmed, B. Saha, M. Miyatake, H. W. Lee and M. Nakaoka "Advanced single-stage soft switching PWM power conditioner with coupled inductor PWM boost chopper cascaded PWM inverter and time-sharing sinusoidal follow-up control scheme."

[14] A. Vázquez, C. Aguilar, F. Canales and M. Ponce, "Integrated power conditioner topology for fuel cell based power supply systems," IEEE, 2008.

[15]A. Vázquez-Blanco, C. Aguilar-Castillo, F. Canales-Abarca and J. Arau-Roffiel, "Two-stage and integrated fuel cell power conditioner: performance comparison,” IEEE, 2009.

[16] Md. S. Munir and T. W. Li, "Residential distribution system harmonic compensation using PV interfacing inverter," IEEE Trans. Smart Grid, vol. 4, no. 2, pp. 816-827, Jun. 2013.

[17] K. Wada, H. Fujita and H. Akagi, "Consideration of a shunt active filter based on voltage detection for installation on a long distribution feeder," IEEE Trans. Ind. Appl., vol. 38, no. 4, pp. 1123-1130, July/Aug. 2002.
[18] P.T Cheng and T.L, "Distributed active filter systems (DAFs): A new approach to power system harmonics," IEEE Trans. Ind. Appl., vol. 42, no. 5, pp. 1301-1309, Sep.- Oct. 2006.

[19] T. L. Lee, J. C. Li and P. T. Cheng, "Discrete frequency tuning active filter for power system harmonic," IEEE Trans. Power Electron., vol. 24, no. 5, pp. 1209-1217,May 2009.

[20] Georgakas, K., Vovos, P., Vovos, N., "Harmonic reduction method for a single-phase dc-ac converter without output filter," IEEE Transactions on Power Electronics, IEEE EARLY ACCESSARTICLES, doi:10.1109/TPEL.2013.2286918,http://iee explore.ieee.org/stamp/stamp.jsp?tp=\&arnumber $=6654312 \&$ isnu mber $=4359240$.

\section{[21] IEEE519-92 Standard.}

[22] M. Karimi-Ghartemani and M. R. Iravani, "A method for synchronization of power electronic converters in polluted and variable-frequency environments," IEEE Tans. Power Syst., vol. 19, no. 3, pp. 1263-1270, Aug. 2004.

[23] M. Karimi-Ghartemani and M. R. Iravani, "A nonlinear filter for online signal analysis in power systems: Applications," IEEE Trans, Power Delivery, vol. 17, no. 2, pp. 617-622, Apr. 2002.

[24] D. Jovcic, “ Phase locked loop system For FACTS," IEEE Trans. Power Syst., vol. 18, no. 3, pp. 1116-1124, 2003.

[25] M. Karimi-Ghartemani, B. T. Ooi and A. Bakshai, "Application of enhanced phase-locked loop system to the computation of synchrophasors," IEEE Trans. Power Delivery, vol. 26, no. 1, pp. 22-32, Jan. 2011.

[26] F. González-Espín, E. Figueres and G. Garcerá, "An adaptive synchronous-reference-frame phase-locked loop for power quality improvement in a polluted utility grid," IEEE Trans. Ind. Electron., vol. 59, no. 6, pp. 2718-2731, Jun. 2012.

[27] I. Carugati, P. Donato, S. Maestri, D. Carrica and M. Benedetti, "Frequency adaptive PLL for polluted single-phase grids," IEEE Trans. Power Electron., vol. 27, no. 5, pp. 23962404, May 2012.

[28] C. S. Vaucher, "An adaptive PLL tuning system architecture combining high spectral purity and fast settling time," IEEE Journ. Solid -State Circ., vol. 35, no. 4, pp. 490502, Apr. 2000.

[29] P. Rodriguez, A. Luna, M. CIobotaru, R. Teodorescu and F. Blaaberg, "Advanced grid synchronization system for power converters under unbalanced and distorted operating conditions," IEEE, 2006. 